\title{
Direct Strength Assessment of Pure Car and Truck Carrier under Maximum Cargo Loads
}

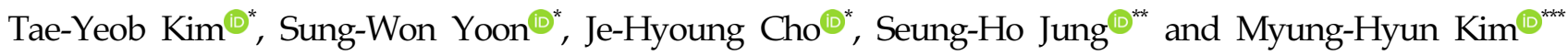 \\ *Department of Ocean ICT \& Advanced Materials, RIMS, Busan, Korea \\ ${ }^{*}$ Future Strategic Planning Headquarters, RIMS, Busan, Korea \\ ${ }^{* \pi k}$ Department of Naval Architecture and Ocean Engineering, Pusan National University, Busan, Korea
}

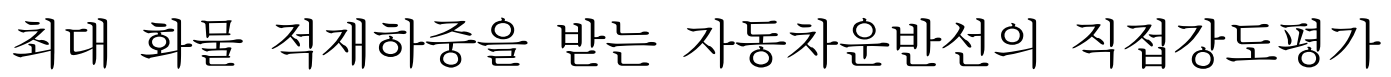

\author{
김태엽@* 윤성원(* 조제형@* 정승호(** 김명현(*** \\ *중소조선연구원 해양IT융복합소재연구본부 \\ **중소조선연구원 전략기획실 \\ 부산대학교 조선해양공학과
}

KEY WORDS: PCTC(Pure car and truck carrier) 자동차운반선, Structural strength analysis 구조강도해석, Cargo load 화물 적재하중, Deflection 처짐, Direct strength assessment 직접강도평가

\begin{abstract}
Yearly world vehicle production has continued to increase, and the global seaborne trade volumes also are recovering. Based on these positive trends, as demand for cargo ships increases in the freight transportation market, Pure car and truck carriers (PCTCs) with large gaps between decks continue to be ordered. The structural analysis of the cargo hold was performed in order to confirm its structural safety in accordance with the guidance for the direct strength assessment of the Korean Register (KR) of Shipping. And, according to the type of cargo, the maximum deflection and structurally weak area that occurred in deck 5 was confirmed. Also, it was found that the weight of the cargo had a significant effect on the deck, the primary members of the deck's structure, and pillars. The results of the structural analysis conducted in this study were added to the existing cargo load planning software. This was done so that the prediction of the maximum stress and the deflection of the deck based on the information about the cargo could be confirmed quickly. In addition, the data will be used as the basic data for rapid information management response to changes in cargo items.
\end{abstract}

\section{1. 서 론}

최근 전 세계 자동차 생산량은 계속 증가하고 있으며, 해상물 동량에서도 회복세를 보이고 있다. 이러한 긍정적인 추세를 바 탕으로 화물운송 시장에서 화물선의 수요가 증가함에 따라 갑 판간 간격이 큰 PCTC(Pure car and truck carrier)도 지속적으로 발주되고 있다. 자동차운반선이란 별도의 크레인을 이용하지 않고 승용차, 트레일러(Trailer), 건설 중장비 등과 같은 차량 및 기타 화물을 운송하는 화물선으로, 수송화물들이 자가 동력으 로 승-하선할 수 있는 선박으로서 전 세계 항로를 통해 최종 목적지까지 저렴한 운임으로 빠르고 안전하게 해상운송하는 것 을 목적으로 건조된 선박이다.

자동차운반선의 구조적 특징을 살펴보면 화물 적재가 용이하 도록 여러 개의 고정식 - 이동식 갑판으로 구성되어 있으며, 차
량들의 원활한 이동을 위해 횡격벽 수를 최소화하거나 횡격벽 을 두지 않는 구조를 채택하여 래킹(Racking) 변형에 대한 횡강 도의 저하가 발생하기 쉬운 구조를 지닌다(Choi et al., 2011).

자동차운반선은 Fig. 1(a)의 하나의 필러(Conventional type)와 Fig. 1(b)의 두 개의 필러(Flexible type)로 지지되는 경우로 구분 되며, 이와 같은 필러의 수는 선적하고자 하는 화물의 종류에 따라 선주에 의해 결정된다(Wang et al., 2018).

필러의 수가 하나인 구조는 선체 길이방향에 대한 차량의 이 동이 원활하지만, 길이가 긴 차량들은 필러가 두 개인 구조보다 길이방향 필러간격이 좁기 때문에 주행방향을 전환시키는데 어 려움이 있다(Kang, 2015).

일반적으로 자동차운반선은 화물선적시 당일 출하량에 따라 선적계획을 수립하기 때문에 사전에 화물수량을 정확히 알 수 없는 문제점이 있으며, 주문수량의 변동성이 심하여 선적량은

Received 16 August 2019, revised 5 December 2019, accepted 19 December 2019

Corresponding author Sung-Won Yoon: +82-51-974-5567, swyoon@rims.re.kr ORCID: https://orcid.org/0000-0003-4563-4675

(c) 2019, The Korean Society of Ocean Engineers

This is an open access article distributed under the terms of the creative commons attribution non-commercial license (http://creativecommons.org/licenses/by-nc/3.0) which permits unrestricted non-commercial use, distribution, and reproduction in any medium, provided the original work is properly cited. 
(a)

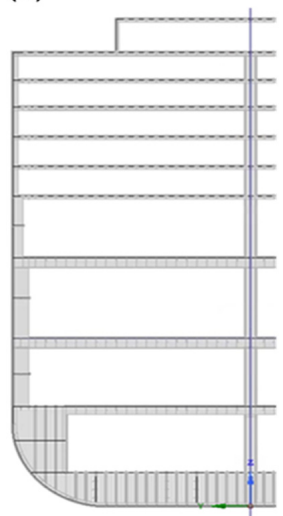

(b)

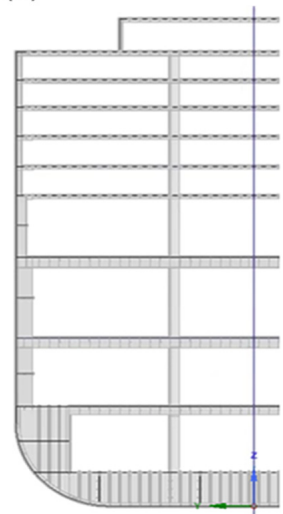

Fig. 1 Pillar system in PCTC cargo hold, (a) one pillar, (b) two pillar

본선적재가 완료될 때까지 변동 가능성이 항시 존재한다. 이로 인해 초기 계획된 적재위치와 실제 적재위치가 다른 경우가 발 생하기 때문에 갑판위치별 허용중량, 복원성 등 선박의 운항 안 정성 계산과 평형수 제어에 대한 정보 등록 관리에 어려움이 존재한다.

국내외 차량 선적 계획 관련 프로그램들은 갑판에 작용하는 적재화물의 중량보다는 전장, 전폭, 전고에 안전거리를 더해 적 재화물을 직사각형으로 간주하여 차량 선적에 주된 목적을 두 고 있어 적재화물 중량에 따른 각 갑판의 처짐이 고려되지 않 고 있다. 이러한 이유로 본 연구의 목적은 차량 선적계획 프로 그램상에서 공간 손실률을 최소화하며 적재화물 정보에 따른 갑판의 예상되는 처짐을 관리자가 간단히 확인할 수 있도록 하 기 위함이다.

본문은 크게 두 가지로 분류하였으며, 상-하부 갑판의 최대 하중상태에 따른 화물창 구조해석과 갑판 중 가장 큰 설계하중 을 받는 Fig. 2에 표시된 5번 갑판을 통해 적재화물의 종류 및 화물수에 따라 갑판에 작용하는 응력과 처짐을 확인하기 위해 고려하였다. 이는 선적량 변동으로 선적계획의 수정이 요구될 경우 초기 적재위치에 다른 화물의 선적으로 인해 발생하는 영 향을 일차적으로 신속히 확인하고자 함이다.

\section{2. 화물창 구조강도해석}

\section{1 화물창 해석모델}

자동차운반선 해석모델은 많은 차량화물을 적재하기 위해 Fig. 2 와 같이 총 13 개의 갑판을 가지며, 높낮이 조절이 가능한 이동식 갑판인 $2,4,6,8$ 번 갑판과 그 외 9 개의 고정식 갑판으 로 이루어져 있다. 이동식 갑판은 일반적으로 승용차를 탑재하 며, 차량화물의 크기에 따라 갑판의 위치를 달리한다( $\mathrm{Na}$ and Chae, 2013). 화물창 구조는 각 갑판에 작용하는 하중을 갑판하 종-횡거더, 필러 및 특설늑골 등으로 보강되어 지지하고 있는 구조를 가지고 있다.

자동차운반선 해석범위는 한국선급의 직접강도평가에 관한 지침 3편 부록 3-2를 참고하여 선박의 길이방향으로 선체 중앙 단면(Midship section)의 2개의 필러를 포함하였다(KR, 2019).

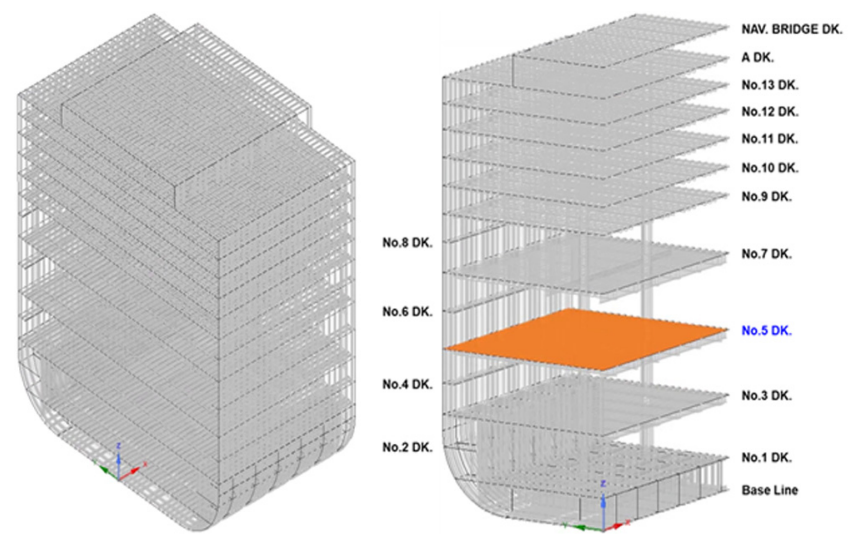

Fig. 2 Cargo hold analysis model of the PCTC

상부 갑판은 일반적으로 중량이 작은 일반차량을 적재하므로 하부 갑판보다 낮은 설계높이를 가지며, 하부 갑판은 상부 갑판 에 비해 중량이 크고 전고가 높은 트럭, 버스, 트레일러, 카세트 (Cassette) 등과 같은 화물을 적재하므로 갑판간 설계 높이가 높 은 구조를 나타내고 있다.

자동차운반선 해석모델은 트레일러와 카세트 등 길이가 긴 화물의 적재가 용이하도록 Fig. 1(b)와 같이 두 개의 필러구조를 채택하였다. 전폭 모델은 판요소 및 보요소를 이용하여 구조를 모델링하였다. 또한, 처짐 및 응력에 대한 설계기준은 등분포하 중과 자체중량이 작용하는 차량갑판 패널의 전체 강도(Global strength)를 기반으로 한다(Alatan and Shakib, 2012).

화물창 해석모델의 요소분할은 길이방향으로는 인접한 특설 늑골 사이를 2 개 이상의 요소로, 폭 방향으로는 종늑골 간격으 로 요소를 분할한다. 그리고 이중저 거더 및 늑판은 깊이방향으 로 3 개 이상으로 분할함을 원칙으로 하는 선급지침을 참고하였 다(KR, 2019).

\section{2 경계조건}

해석모델의 경계조건은 실제 구조와 같은 거동을 표현할 수 있도록 적용하며, 선급지침을 참고하여 설정한 경계조건은 Fig. 3 및 Table 1에 나타내었다(KR, 2019).

화물창 모델의 선체 길이방향 양단면은 대칭조건을 적용하였 으며, 횡변위(Line L) 및 상하변위(Line S)의 모든 절점은 Table 1 을 참고하여 구속하였다.
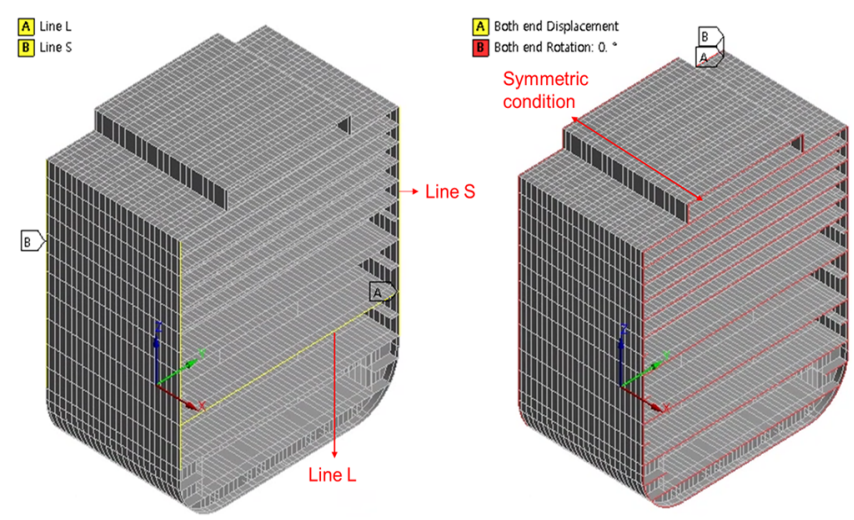

Fig. 3 Boundary conditions for analysis model (Isometric view) 
Table 1 Boundary conditions (Asymmetric)

\begin{tabular}{|c|c|c|c|c|c|c|}
\hline \multirow[b]{2}{*}{ Position } & \multicolumn{3}{|c|}{ Displacement } & \multicolumn{3}{|c|}{ Rotation } \\
\hline & $U_{x}$ & $U_{y}$ & $U_{z}$ & $\theta_{x}$ & $\theta_{y}$ & $\theta_{z}$ \\
\hline Both ends of the model & 1 & 0 & 0 & 0 & 1 & 1 \\
\hline Line $\mathrm{L}$ & 0 & 1 & 0 & 0 & 0 & 0 \\
\hline Line $\mathrm{S}$ & 0 & 0 & 1 & 0 & 0 & 0 \\
\hline
\end{tabular}

(Note) $1:$ Fixed, $0:$ Free

\section{3 적용하중 및 하중조건}

자동차운반선의 구조해석을 위해 고려되는 하중으로는 상하부 갑판의 최대 하중상태, 횡방향 및 종방향 비대칭 하중, 평 형수 적재상태와 침수상태가 있으며, 선급지침의 하중조건에 따라 확인하고자 하는 대상부재에 적용하게 된다.

본 연구에서는 상-하부 갑판의 최대 화물 하중상태를 하중 조건으로 적용하여 갑판 및 주부재를 평가하였다. Table 2 를 참 고하여 화물창에 갑판별 규정된 설계하중을 적용하며, 선측 및 선저에 작용하는 선체 외부하중으로 정수압과 파랑 변동 하중 을 고려하였다(KR, 2019).

Table 2 Load cases of Ro-Ro and car carrier

\begin{tabular}{|c|c|c|c|c|}
\hline \multirow{2}{*}{ Load case } & \multirow{2}{*}{ Case } & \multicolumn{2}{|c|}{ External load } & \multirow{2}{*}{$\begin{array}{c}\text { Cargo } \\
\text { load }\end{array}$} \\
\hline & & $\begin{array}{l}\text { Still water } \\
\text { load }\end{array}$ & $\begin{array}{c}\text { Wave } \\
\text { induced load }\end{array}$ & \\
\hline $\begin{array}{l}\text { Maximum cargo on } \\
\text { lower part of } \\
\text { section in upright } \\
\text { condition }\end{array}$ & F-1 & $d_{s}{ }^{1)}$ & $W_{c}^{2)}$ & $\begin{array}{l}\text { Design } \\
\text { uniform } \\
\text { load }\end{array}$ \\
\hline $\begin{array}{l}\text { Maximum cargo on } \\
\text { upper part of } \\
\text { section in upright } \\
\text { condition }\end{array}$ & $\mathrm{F}-2$ & $d_{s}{ }^{1)}$ & $W_{c}^{2)}$ & $\begin{array}{l}\text { Design } \\
\text { uniform } \\
\text { load }\end{array}$ \\
\hline
\end{tabular}

\section{4 화물창 해석결과}

자동차운반선 화물창 구조는 적재화물을 종방향 및 횡방향 갑판 주부재들과 필러에 의해 갑판이 지지될 수 있도록 설계되 어 있으며, 상- 하부 갑판의 최대 하중상태를 적용하여 갑판 및 갑판 주부재들의 최대 처짐과 응력이 발생하는 부위를 확인하 였다.

한국선급에서 규정된 자동차운반선의 직접강도평가 지침을 참고하여 해석 조건을 적용하였으며, 갑판별 설계하중에 대한 해석결과는 다음과 같다.

하부 갑판에 최대 설계하중이 작용하는 경우 갑판의 처짐 및 응력은 5 번 갑판의 필러 사이인 갑판 중앙부에서 $214.11 \mathrm{MPa}$ 와 $62.813 \mathrm{~mm}$ 로 가장 큰 결과를 보이는 것을 Fig. 4 를 통해 확인할 수 있다. 이는 좌·우현 방향의 갑판은 주부재와 선측 늑골로 보강되어 있으나, 갑판의 중앙부는 주부재만으로 지지하기에 화물과 자중에 의한 영향이 더 크게 작용하여 비교적 많은 양 의 처짐이 발생한 것으로 보인다. 5 번 갑판의 경우 자동차운반

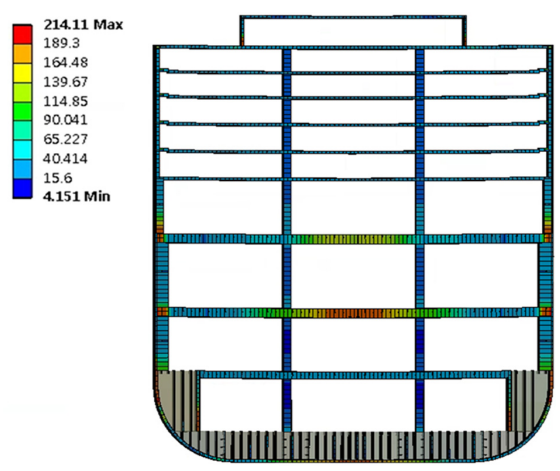

(a) Equivalent stress

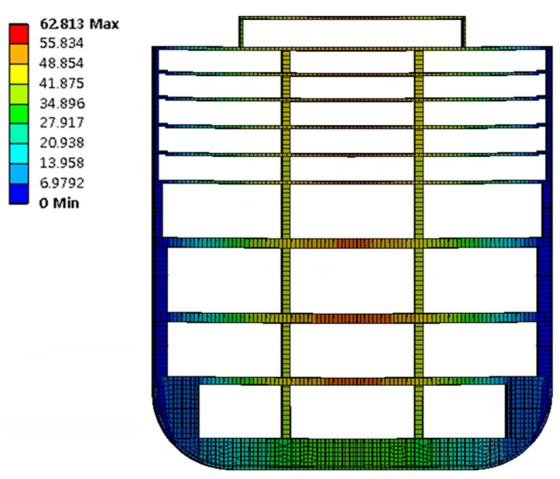

(b) Total deformation

Fig. 4 FEA results of maximum cargo on lower part of section in upright condition (F-1)

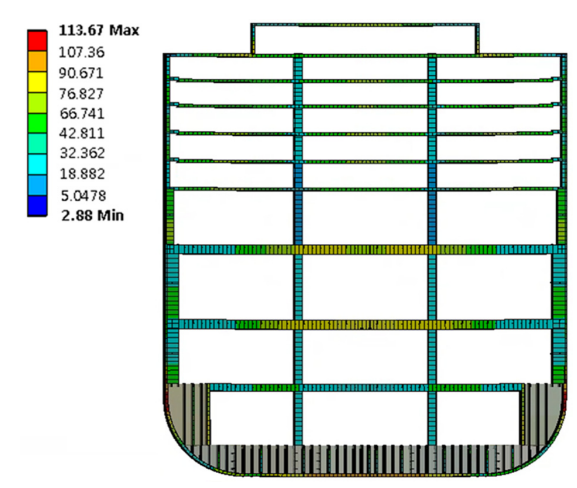

(a) Equivalent stress

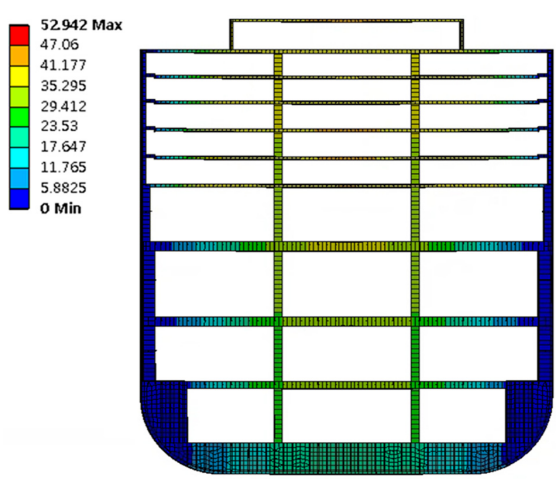

(b) Total deformation

Fig. 5 FEA results of maximum cargo on upper part of section in upright condition (F-2) 
선 갑판 중에서 가장 큰 설계하중이 작용하기 때문에 상대적으 로 5 번 갑판 이외의 갑판에 적용되는 설계하중에 비해 큰 응력 과 처짐의 결과를 보이는 것으로 판단된다.

Fig. 5의 상부 갑판 최대 하중상태에서는 갑판의 설계하중이 하부 갑판들보다 낮고 필러와의 간격이 좁기 때문에 $52.942 \mathrm{~mm}$ 로 서 최대 처짐이 Fig. 4(b)보다 낮게 나타났다. 또한, 갑판 주부재 와 필러가 연결되는 접합부에서 상부 갑판하중에 의한 113.67 $\mathrm{MPa}$ 의 최대 응력이 발생하였으나 허용응력 범위를 만족하는 것 으로 나타났다.

상기 해석결과를 통해 최대 처짐이 발생하는 5 번 갑판은 선 주가 요구하는 갑판 설계하중에 따른 처짐 허용치를 만족하고 있으나, 초기의 선적계획이 변경될 경우를 고려하여 적재화물 의 종류를 달리함으로써 5 번 갑판의 적재구역별 처짐에 따른 갑판과 주부재의 안전성을 3 장에서 확인해 보았다.

\section{5 번 갑판의 적재화물별 구조강도해석}

화물운송 특성상 주문수량 변동으로 인해 선적량이 항시 변 경될 수 있으므로, 선적계획이 수정되었을 경우 초기 계획된 화 물의 적재위치에 다른 종류의 화물이 적재되는 경우가 발생할 수 있다. 이는 선박의 복원성, 운항안정성 등을 위해 기존 적재 화물 위치의 변경을 초래할 수 있으며, 실시간 적재 정보 관리 와 출항의 지연을 야기한다. 이러한 문제들로 차량과 기타 화물 의 제원에 따른 갑판구역 내 선적만을 목적으로 하는 선적 계 획 프로그램이 아닌 적재품목 변경에 따른 빠른 대응을 위해 각 화물에 따라 갑판에 발생하는 응력과 처짐 예측이 가능하도 록 가이드라인를 제시하기 위해 수행되었다.

\section{1 경계조건 및 하중조건}

적재화물 종류에 따라 5번 갑판에서 발생하는 응력 및 처짐 을 확인하기 위한 지점은 총 14 개로 선정하였으며, 필러가 포함 된 영역인 P-1에서 P-7 지점과 필러가 없는 갑판의 중앙부인 $\mathrm{P}-8$ 에서 P-14 지점으로서 필러의 영향을 고려하였다.

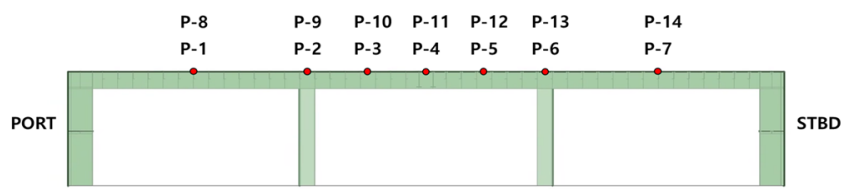

(a) Front view

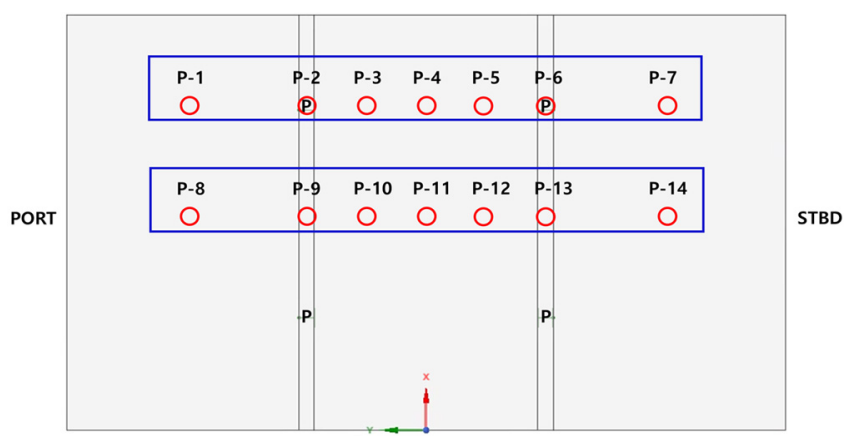

(b) Top view

Fig. 6 Check points of No. 5 deck
Table 3 Cargo details for load cases

\begin{tabular}{ccccc}
\hline \hline & Case 1 & Case 2 & Case 3 & Case 4 \\
\hline $\begin{array}{c}\text { Overall length } \\
{[\mathrm{mm}]}\end{array}$ & 4,770 & 7,660 & 12,230 & 7,500 \\
$\begin{array}{c}\text { Overall width } \\
{[\mathrm{mm}]}\end{array}$ & 1,890 & 2,490 & 4,100 & 3,600 \\
$\begin{array}{c}\text { Empty vehicle weight } \\
{[\mathrm{t}]}\end{array}$ & 1.785 & 15 & 53.3 & 56 \\
\hline
\end{tabular}

Table 4 Number of cargoes by load conditions

\begin{tabular}{ccccc}
\hline \hline & $\begin{array}{c}\text { Case } 1 \\
(\mathrm{~A})\end{array}$ & $\begin{array}{c}\text { Case } 2 \\
(\mathrm{~B})\end{array}$ & $\begin{array}{c}\text { Case } 3 \\
(\mathrm{C})\end{array}$ & $\begin{array}{c}\text { Case } 4 \\
(\mathrm{D})\end{array}$ \\
\hline $\mathrm{L} / \mathrm{C} 1$ & 16 & 12 & 6 & 9 \\
$\mathrm{~L} / \mathrm{C} 2$ & 8 & 6 & 2 & 3 \\
$\mathrm{~L} / \mathrm{C} 3$ & 16 & 12 & 6 & 9 \\
$\mathrm{~L} / \mathrm{C} 4$ & 48 & 36 & 18 & 27 \\
\hline
\end{tabular}

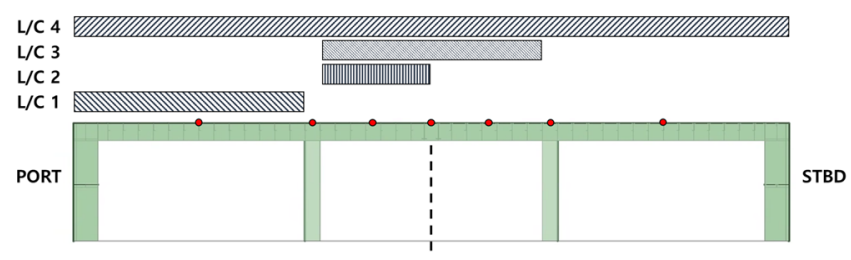

Fig. 7 Load cases (L/C) of No. 5 deck

Fig. 6(a)와 Fig. 6(b)에서 상세한 지점을 확인할 수 있다. 경계 조건은 자동차운반선 화물창의 5 번 갑판만을 고려하였으므로 2.2장과 동일하게 설정하였다.

적용하중은 Table 3 의 적재품목에 따른 전장, 전폭을 통해 갑 판구역 내 최대로 적재할 수 있는 화물수를 확인하여 Table 4와 같이 선정하였다. Table 3의 적재품목은 승용차(Case 1), 덤프트 럭(Case 2), 중대형 굴삭기(Case 3), 전차(Case 4)로서, 설계단계 에서 고려한 적재화물과 고려하지 않은 적재화물을 함께 적용 하였다. 이는 극한 하중조건에서의 갑판위치별 처짐 및 응력을 확인하기 위함이며, 화물수 역시 실적재보다 많은 수를 산정하 였다. 또한, 초기 계획에 없는 화물로 변경되어 선적될 경우 프 로그램상에서 간단히 적재화물의 정보만으로 갑판과 주부재에 작용하는 피크 하중(Peak load) 및 최대 처짐에 의한 손상을 예 측하기 위해 고려되었으며, 본 장에서는 5 번 갑판만을 해석대상 으로 선정하였기 때문에 화물의 전고는 고려하지 않는 것으로 가정하였다.

Fig. 7 에서 총 4 개(L/C $1, \mathrm{~L} / \mathrm{C} 2, \mathrm{~L} / \mathrm{C} 3, \mathrm{~L} / \mathrm{C} 4)$ 의 하중조건에 대한 적용범위를 확인할 수 있다.

\section{2 해석결과}

적재품목별 4 개의 하중조건에 따라 갑판에 발생하는 구조 취 약부 및 갑판의 처짐을 확인하였으며, 5 번 갑판의 설계허용응력 은 $3 \mathrm{t} / \mathrm{m}^{2}$ 이다. 갑판의 최대 처짐 허용량은 $50 \mathrm{~mm}$ 를 기준으로 하 였다. Table 3의 적재품목별 해석결과의 경향이 유사하게 나타 나므로 Fig. 8-11은 최대 하중이 작용하는 Case 4에 대한 결과를 대표적으로 나타내었다. 또한, Case 4의 14개 지점에 대한 응력 
Table 5 Equivalent stress results of Case 4 [Unit : MPa]

\begin{tabular}{ccccccccccccccc}
\hline \hline & P-1 & P-2 & P-3 & P-4 & P-5 & P-6 & P-7 & P-8 & P-9 & P-10 & P-11 & P-12 & P-13 & P-14 \\
\hline L/C 1 & 35.876 & 47.618 & 17.049 & 11.499 & 3.269 & 15.961 & 2.923 & 29.804 & 17.096 & 10.248 & 5.64 & 2.131 & 2.202 & 1.995 \\
L/C 2 & 5.134 & 53.594 & 25.207 & 21.384 & 8.743 & 37.958 & 3.261 & 3.21 & 11.329 & 11.156 & 11.624 & 5.205 & 6.939 & 1.932 \\
L/C 3 & 6.74 & 108.01 & 40.612 & 50.905 & 40.364 & 108.12 & 6.742 & 6.891 & 21.469 & 20.483 & 30.31 & 19.587 & 21.47 & 6.89 \\
L/C 4 & 36.802 & 140.35 & 49.352 & 59.91 & 49.136 & 140.47 & 36.807 & 26.109 & 34.102 & 24.35 & 28.62 & 23.453 & 34.103 & 26.103 \\
\hline
\end{tabular}

Table 6 Total deformation results of Case 4 [Unit : mm]

\begin{tabular}{ccccccccccccccc}
\hline \hline & P-1 & P-2 & P-3 & P-4 & P-5 & P-6 & P-7 & P-8 & P-9 & P-10 & P-11 & P-12 & P-13 & P-14 \\
\hline L/C 1 & 10.58 & 1.223 & 1.867 & 2.384 & 1.563 & 0.296 & 0.824 & 13.98 & 11.502 & 6.393 & 3.378 & 2.063 & 1.505 & 0.941 \\
L/C 2 & 1.162 & 0.931 & 5.651 & 6.927 & 4.468 & 0.563 & 0.694 & 2.362 & 7.465 & 9.442 & 8.577 & 6.674 & 4.402 & 1.271 \\
L/C 3 & 0.786 & 1.683 & 12.374 & 16.922 & 12.374 & 1.682 & 0.786 & 2.821 & 13.613 & 19.805 & 21.355 & 19.795 & 13.613 & 2.821 \\
L/C 4 & 10.164 & 2.575 & 12.986 & 17.821 & 12.986 & 2.575 & 10.164 & 15.092 & 22.414 & 23.88 & 23.726 & 23.87 & 22.414 & 15.092 \\
\hline
\end{tabular}

과 처짐의 값은 Table 5 와 Table 6 에 제시하였다.

Fig. 8은 L/C 1에 대한 해석결과로서 $\mathrm{L} / \mathrm{C} 1$ 이 작용하는 범위 에 하중이 집중되어 선측 외판에 위치한 늑골에서 $170.25 \mathrm{MPa}$ 의 최대응력이 발생하였다. 처짐은 갑판을 지지하고 있는 필러 (P-2) 라인과 선체 외판 사이의 중간지점인 P-8에서 $13.98 \mathrm{~mm}$ 로 가장 큰 처짐이 나타났다. 이는 $\mathrm{L} / \mathrm{C} 1$ 이 작용하는 갑판의 $\mathrm{P}-1$, P-8 지점에는 연직방향으로 지지하는 필러가 없기 때문에 각각 $10.58 \mathrm{~mm}$ 와 $13.98 \mathrm{~mm}$ 의 최대 처짐이 발생하는 것으로 보이며, 요구되는 갑판의 최대 처짐 허용치를 만족하고 있는 것으로 확 인되었다.

Fig. 9-11은 각각 $\mathrm{L} / \mathrm{C} 2,3,4$ 에 대한 결과를 나타낸 것으로 자 세한 결과값은 Table 5와 Table 6에서 확인이 가능하며, 3 가지 하중조건에 대한 모든 해석결과에서 적용하중으로부터 연직방 향으로 갑판을 지지하고 있는 필러부에서 최대 응력이 발생하 였다. 이는 갑판상에 작용하는 하중에 의해 압축응력이 발생함 으로서 거더와 필러의 연결부에서 주부재에 발생하는 굽힘 모 멘트에 의한 전단응력이 최대로 나타난 것으로 보인다. 또한,
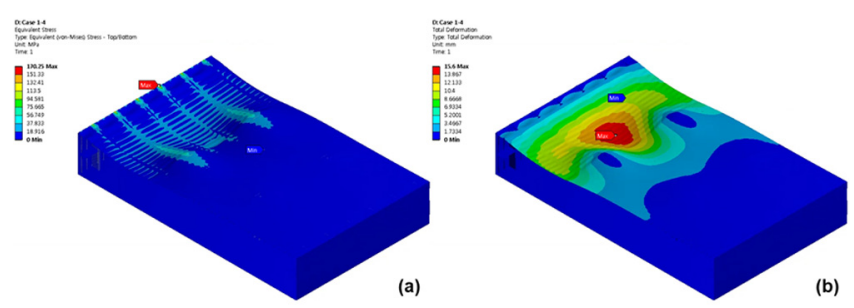

Fig. 8 FEA results of L/C 1 for Case 4, (a) Equivalent stress, (b) Total deformation

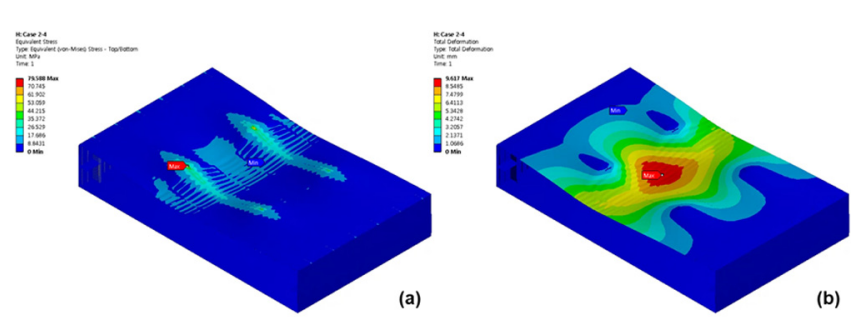

Fig. 9 FEA results of L/C 2 for Case 4, (a) Equivalent stress, (b) Total deformation

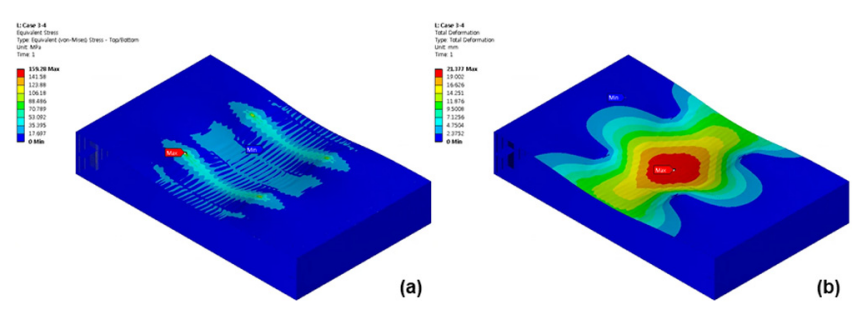

Fig. 10 FEA results of L/C 2 for Case 4, (a) Equivalent stress, (b) Total deformation

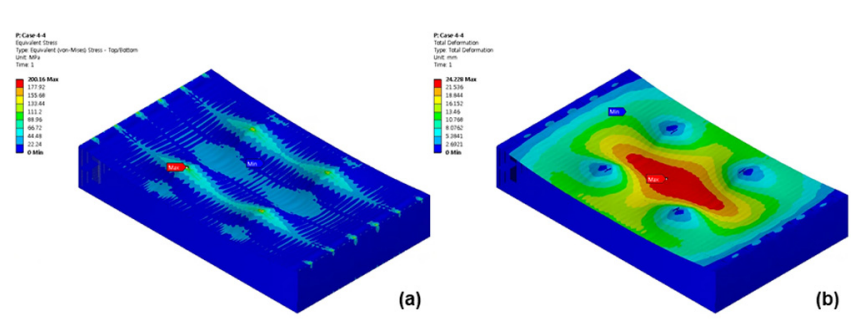

Fig. 11 FEA results of L/C 2 for Case 4, (a) Equivalent stress, (b) Total deformation

적재화물의 하중이 갑판과 주부재에 직접적으로 작용하고 있기 때문에 횡방향 및 종방향 갑판 주부재를 연직으로 지지하는 유 일한 부재인 필러에서 다른 주부재에 비해 큰 응력이 발생하는 결과를 나타내었다.

Fig. 9(b)에서 Fig. 11(b)에 대한 처짐은 Fig. 8(b)의 결과와 같 이 필러가 없는 위치에서 갑판과 횡방향 주부재의 큰 처짐이 발생하였다. 또한, $\mathrm{L} / \mathrm{C} 4$ 에 대한 해석결과를 통해 고려한 적재 품목 중 가장 큰 중량을 가진 Case 4 에서도 갑판의 허용응력에 미치지 못하므로 구조적으로 안전한 결과를 보였다. 해석결과 를 통해 5 번 갑판과 주부재에서 최대 처짐과 응력이 발생하는 부위에 대해 파악할 수 있었으며, 이는 향후 선적 계획 프로그 램상에서 선적 화물의 위치를 선정할 시 최대 처짐과 응력이 발생하는 곳에서는 큰 중량을 가진 화물들을 회피하여 선적할 수 있도록 가이드라인으로서 제시할 수 있을 것으로 판단된다.

Fig. 12에서 Fig. 15는 5번 갑판의 총 14개 지점(P-1 14)에서 발생하는 응력 및 처짐에 대한 최대 결과값을 도시해놓았다.

Fig. 12(a)에서는 Fig. 8(a)의 결과를 통해 언급한 바와 같이 

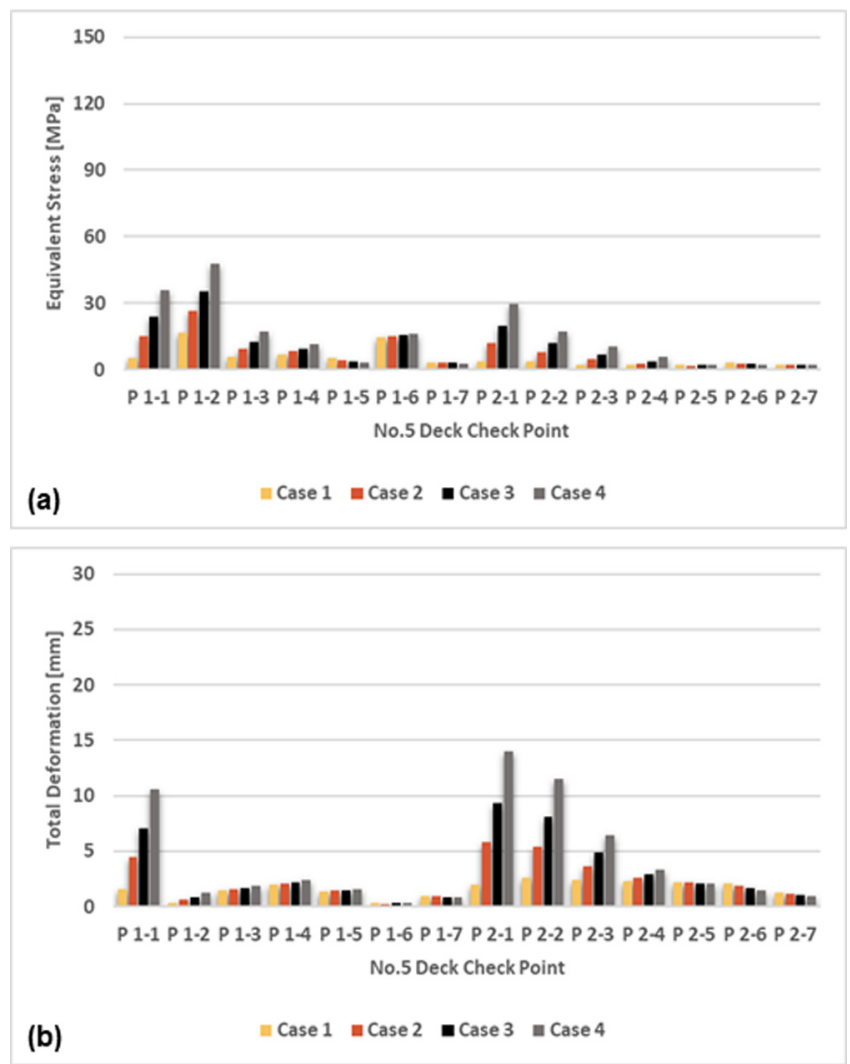

Fig. 12 FEA results of L/C 1, (a) Equivalent stress, (b) Total deformation
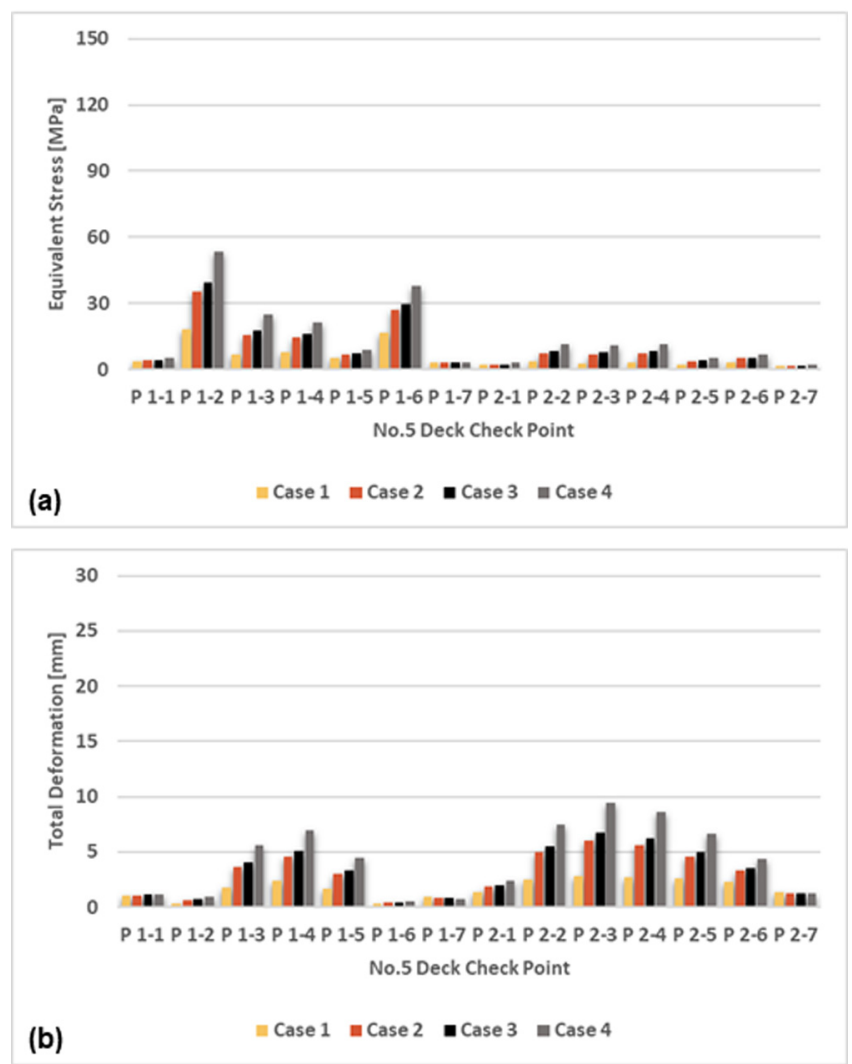

Fig. 13 FEA results of L/C 2, (a) Equivalent stress, (b) Total deformation
$\mathrm{L} / \mathrm{C} 1$ 의 하중이 작용함으로서 외판의 늑골부에서 최대 하중이 나타나며, 확인한 14 개 지점에서는 갑판부만 고려되므로 모든 품목(Case 1 4)에서 필러가 위치한 P-2에서 최대 응력이 발생하 였다. 이는 외판과 필러 사이의 갑판 중앙부에 작용하는 연직하 중으로 인해 갑판 주부재를 통해 전달되는 전단력이 필러에 집 중되기 때문으로 판단된다.

Fig. 12(b)는 변형에 대한 결과로서 P-8에서 최대 처짐이 발생 하며, P-1과 P-9에서도 그에 준하는 처짐이 나타났다. 이는 Fig. 8(b)의 결과와 같이 연직방향으로 지지해주는 유일한 부재인 필 러가 없으므로 처짐이 집중되는 것으로 확인된다.

Fig. 13에서 Fig. 15의 14개 지점에 대한 결과를 통해 P-2와 P-6의 필러부에서 최대 응력이 발생하였으며, 최대 처짐은 필러 가 없는 갑판 중앙부인 P-4 및 P-11 지점에서 확인되었다. 처짐 의 경우 최대 처짐 지점인 P-11을 기준으로 갑판의 좌·우현 방 향으로 점차 처짐이 감소하는 경향을 나타내었으며, 이는 필러 의 영향으로 연직방향에 대한 갑판의 처짐을 최소화해주는 것 으로 보인다.

Table 5-6은 Fig. 12에서 Fig. 15의 Case 4에 대한 하중조건별 응력과 처짐값을 대표적으로 나타내었으며, 상기 결과들과 부 합하는 것을 수치적으로 확인할 수 있다.

상기 결과들을 통해 적재품목이 변경되어도 갑판 및 갑판 주 부재에 발생하는 응력 및 처짐의 결과는 모두 유사한 경향을 나타내고 있는 특징이 있다. 이를 통해 갑판, 주부재 및 필러에 적재중량이 큰 영향을 미치는 것을 재차 확인하였으며, 갑판의 처짐 및 응력이 최대로 발생하는 곳에서는 주부재의 파손을 야

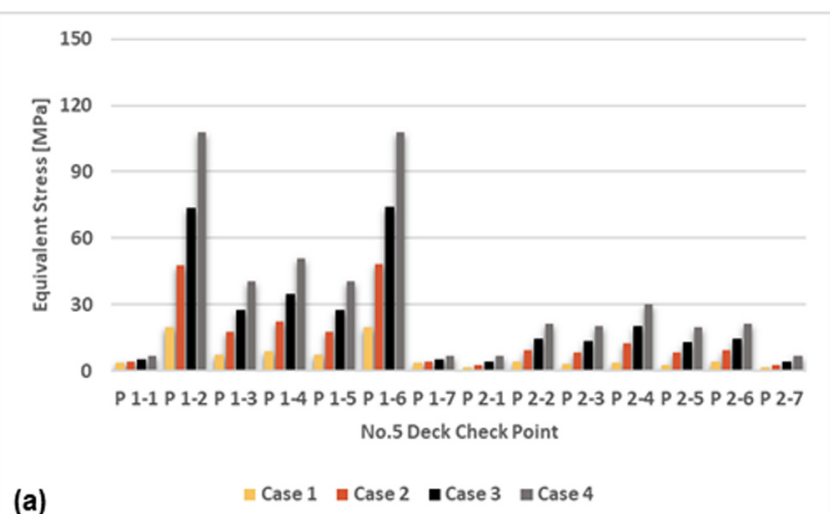

(a)

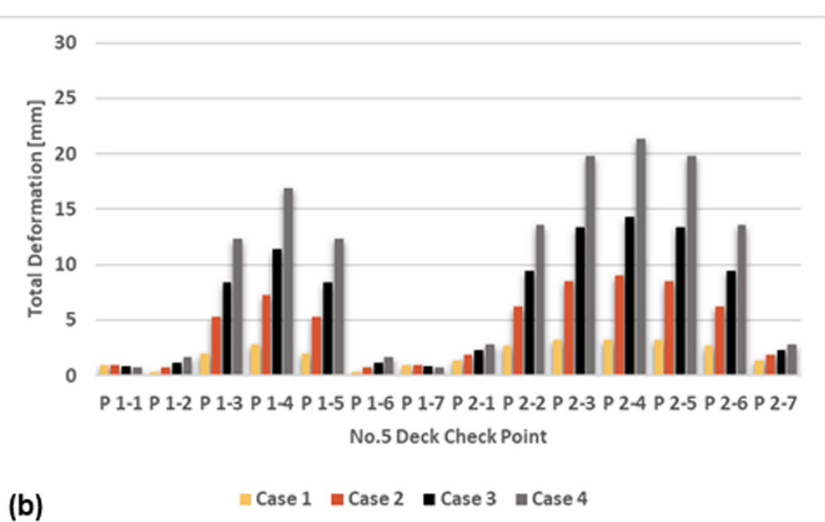

Fig. 14 FEA results of L/C 3, (a) Equivalent stress, (b) Total deformation 

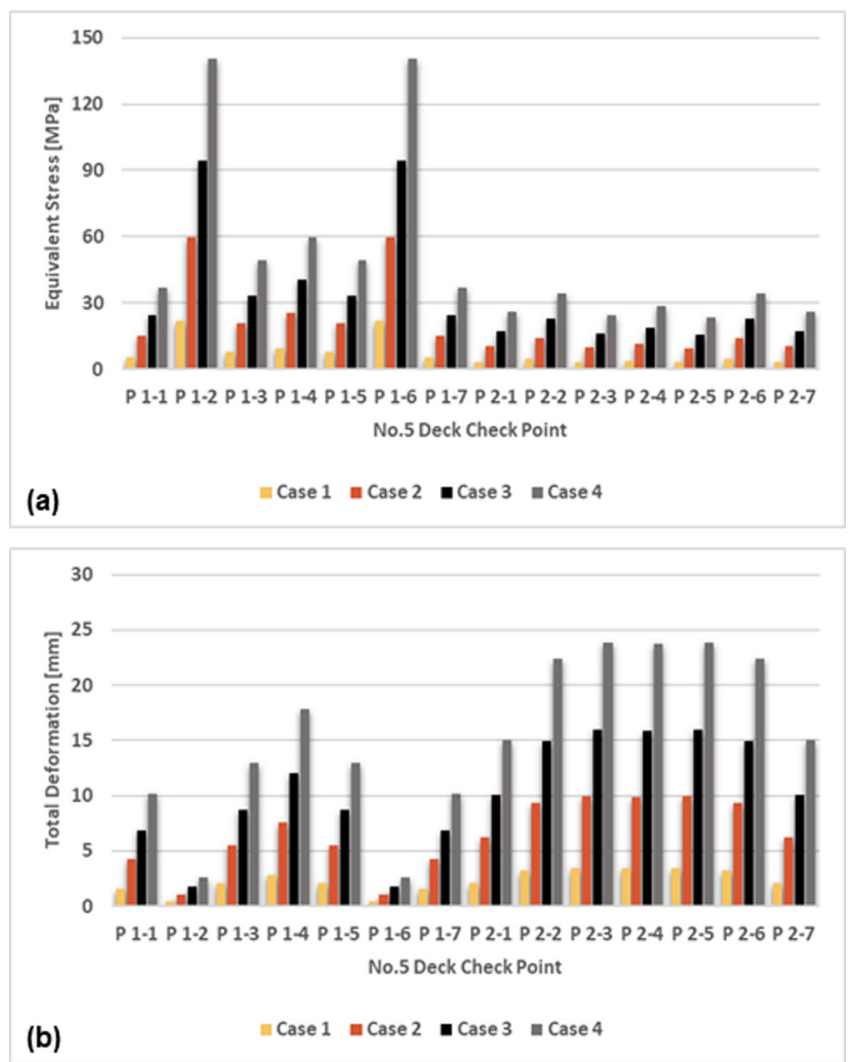

Fig. 15 FEA results of L/C 4, (a) Equivalent stress, (b) Total deformation

기하는 하중이 발생할 수 있으므로 과적을 삼가 하여야 한다. 이는 선체와 승조원의 안전을 위협하는 요인이 되기 때문에, 작 업관리자들은 갑판 내 적재화물들이 설계하중 범위를 넘어서지 않는지 사전에 충분히 검토하여 선적할 필요가 있다.

\section{4. 결 론}

본 연구에서는 상-하부 최대 하중상태에서의 자동차운반선 선체 중앙단면의 구조 안전성 및 적재품목 종류에 따라 5 번 갑 판에 발생하는 최대 처짐 및 응력 발생 위치를 통해 구조 취약 부를 확인하였으며, 다음과 같은 결론을 도출하였다.

(1) 자동차운반선 화물창에 대한 직접강도해석은 상-하부 최 대 하중상태를 적용하였으며, 모두 갑판 주부재와 필러가 연결 되는 부위에서 설계하중에 의한 최대 응력이 발생하였으며, 최 대 처짐은 필러가 없는 갑판 중앙부에서 나타났으나 요구하는 처침 허용치를 만족하므로 구조적으로 안전하다고 평가하였다.

(2) 적재품목에 따라 5 번 갑판에 발생하는 구조 취약부 및 최
대 처짐을 확인하였으며, 갑판, 주부재 그리고 필러에는 화물중 량이 큰 영향을 미치는 것을 알 수 있었다. 또한, 갑판과 주부재 를 연직방향으로 지지하는 유일한 부재인 필러가 없는 곳에서 최대 처짐이 발생하였으며, 최대 처짐이 발생하는 지점을 기준 으로 좌·우현 방향으로 갈수록 필러와 선측 늑골의 영향으로 점차 처짐이 감소하는 경향을 보였다. 그리고 갑판에 발생하는 최대 응력은 주부재를 통해 전달되는 전단력으로 인해 필러에 하중이 집중되어 나타나는 것을 확인하였다.

(3) 본 연구를 통해 수행된 구조해석 결과는 기존의 선적만을 목적으로 하는 차량 선적 계획 프로그램에 추가되어 화물정보 에 따라 갑판에 발생하는 응력과 최대 처짐을 간단히 예측하기 위함이며, 적재품목의 변경에 따른 신속한 정보관리 대응을 위 한 기초자료로서 활용될 계획이다.

\section{후 기}

이 논문은 2019년도 정부(과학기술정보통신부)의 재원으로 정 보통신산업진흥원의 지원을 받아 수행된 연구임.

(S0249-19-1021, 차량운반선 대상 하역 최적화 및 운항 안전성 지원 서비스 개발)

\section{References}

Alatan, B., Shakib, H., 2012. Parametric Design and Optimization of Steel Car Deck Panel Structures. Master of Science Thesis, Chalmers University of Technology, Gothenburg Sweden, Report No. X-12/280.

Choi, J.I., Kim, C.W., Yeon, K.J., Choi, Y.H., Han, J.Y., 2011. Structural Safety Assessment of Pure Car and Truck Carrier(1). Proceedings of the Korean Association of Ocean Science and Technology Societies, Busan Korea, 1106-1110.

Kang, D.K., 2015. A Study on the Determination of Scantlings of Primary Members on Deck Structure of Pure Car and Truck Carrier. Master's Thesis, University of The Ulsan.

Korean Register(KR), 2019. Rules for the Classification of Steel Ships Part 3 Hull Structures/Annex 3-2 Guidance for the Direct Strength Assessment.

Na, Y.M., Chae, W.K., 2013. Study for Support Structure of Liftable Car Deck on PCTC. Special Issue of the Society of Naval Architects of Korea, 60-65.

Wang, W., Ma, H., Xu, M.N., Chen, D.Y., Xie, Y.H., Li, G.Q., 2018. Research on Structural Strength of 7800 PCTC under Flexible Design. IOP Conference Series: Materials Science and Engineering. 398(1). IOP Publishing. 